\title{
Meninas e meninos na Educação Infantil: \\ uma questão de gênero e poder*
}

\author{
Claudia Vianna** \\ Daniela Finco***
}

\section{Resumo}

Ao discutir os relatos de professoras e observar suas ações frente às meninas e aos meninos, este artigo trata das relações de gênero e poder presentes nos processos de socialização de crianças pequenas e analisa as estratégias voltadas para a normalização e o controle das expressões corporais de meninas e meninos. Ao buscar compreender como ocorria a educação de meninos $e$ meninas que transgrediam as fronteiras do que lhes era imposto, verificamos como as características aparentemente naturalizadas $e$ direcionadas à masculinidade $e$ à feminilidade são resultantes de muitos esforços para deixar marcas distintas no corpo, no comportamento e nas habilidades dessas crianças.

Palavras-chave: Educação Infantil, Gênero, Práticas Docentes.

\footnotetext{
" Recebido para publicação em dezembro de 2008, aceito em abril de 2009.

** Professora da Faculdade de Educação da Universidade de São Paulo. cpvianna@usp.br

****Doutoranda em Educação, Faculdade de Educação da Universidade de São Paulo.danielafinco@yahoo.com.br
} 
Girls and Boys in Childhood Education:

Gender and Power Relationships

\begin{abstract}
Based on interviews with teachers and on the observation of their work with girls and boys, this article deals with the gender and power relationships in the process of early childhood socialization and analyzes the strategies that are used to promote the normalization and control of body expressions o girls and boys. In the process of trying to understand how was developed the education of boys and girls who transgressed the frontiers which were imposed on them, we observed how the apparently naturalized characteristics of masculinity and of femininity are the result of many efforts to mark differently the body, the behavior and the skills of these children.
\end{abstract}

Key-words: Childhood Education, Gender Relationships, Teacher Practices. 
Ainda hoje algumas pesquisas sustentam que, para além das diferenças anatômicas entre os sexos, o cérebro de meninas e de meninos processa de modo essencialmente distinto a linguagem, as informações, as emoções, o conhecimento e tantas outras características, tidas como naturais, que conduziriam às distinções de comportamento e de habilidade cognitiva.

Mas será, de fato, possível afirmar que as competências, os atributos $e$ os comportamentos deles decorrentes são originalmente configurados conforme cada sexo? Será verdade o que nós aprendemos sobre as justificativas biológicas para as diferentes habilidades de meninas e meninos?

Em ampla investigação sobre as construções do sexo e do corpo sexuado, Anne Fausto-Sterlling (2000) - professora de biologia e estudos do gênero do Departamento de Biologia Molecular e Celular e Bioquímica da Universidade Brow, em Rhode Island, Estados Unidos - cita inúmeras pesquisas que atestam a existência de uma anatomia cerebral específica para cada sexo. Daí viria o fundamento para atribuir às mulheres e a seu largo corpo caloso ${ }^{1}$ a intuição, a falta de aptidão para ciências exatas, a ampla habilidade verbal e o uso simultâneo de ambos os hemisférios cerebrais. Aos homens, em geral, atribui-se melhor desempenho espaço-visual, matemático e científico. Articulando biologia, medicina e ciências sociais, a autora revela ainda como essas pesquisas usam as relações sociais para estruturar a natureza e, ao mesmo tempo, reduzem o mundo social a ela. Em outras palavras, passam da discussão das diferenças externas e do

${ }^{1}$ O cérebro divide-se no meio em dois hemisférios cerebrais. Cada hemisfério é especializado para algumas tarefas específicas. Eles se comunicam através de um feixe que tem entre 200 e 250 milhões de fibras nervosas chamado de "corpo caloso". Portanto, o encéfalo é constituído de vários componentes, sendo o neocórtice uma das regiões mais complexas, que se divide nesses dois hemisférios, os quais estão unidos por várias comissuras, ou seja, bandas de fibras nervosas que ligam certas regiões do hemisfério esquerdo a zonas similares no hemisfério direito. A maior dessas comissuras toma o nome de corpo caloso (Fausto-Sterlling, 2000). 
ambiente social para as diferenças internas, do organismo biológico, e seus efeitos sobre o que se entende por masculinidade e feminilidade.

Refletir sobre os fundamentos dessas afirmações no âmbito da educação e, mais especificamente, da educação infantil exige o questionamento de suas origens e do peso do caráter biológico na construção das diferenças. Isso pressupõe, por exemplo, indagar a respeito da interferência e do papel da cultura nos processos de socialização e de formação de meninas e meninos desde suas primeiras experiências de vida na instituição escolar.

No âmbito dos modelos cognitivos, é possível comprovar que as diferenças no desempenho em matemática ou na capacidade de linguagem resultam de diferenças cerebrais de cada sexo, consideradas inatas? No campo das relações e dos comportamentos infantis, podemos mesmo supor que elas necessariamente preferem as bonecas e eles os carrinhos? Elas foram feitas para brincar de roda e eles de futebol?

A perspectiva sociocultural permite centrarmos nosso olhar nas formas de controle do corpo infantil, um processo social $e$ culturalmente determinado, permeado por formas sutis, muitas vezes não percebidas. Poderíamos, então, dizer que as características tidas pela tradição como naturalmente masculinas ou femininas resultam de esforços diversos para distinguir corpos, comportamentos e habilidades de meninas e meninos.

Pesquisadoras e pesquisadores, como Carmen Soares (2002), Alfredo Veiga-Neto (1996), Andrés Zarankin (2002) e Tarcísio Mauro Vago (2002), nos ajudam a pensar no corpo como um lugar de inscrição da cultura; nos dizeres de Carmen Soares e Andrés Zarakin (2004:25), um lugar que revela toda a "dinâmica de elaboração de códigos, técnicas, pedagogias, arquiteturas e instrumentos desenvolvidos para submetê-lo a normas".

O corpo é alvo das práticas disciplinares. Há um aparato instrumental e institucional que busca constantemente disciplinálo quando busca fugir e escapar, seja por meio de mecanismos 
repressivos, seja por um discurso que impõe às crianças uma imagem estigmatizada de si mesmas (Frangella, 2000).

A influência dos processos de socialização sobre a cognição, o comportamento $e$ as habilidades motoras de ambos os sexos vem sendo reconhecida por pesquisadores de várias áreas. E a denúncia do pretenso caráter fixo e binário de categorias como feminino e masculino, contido nas explicações biológicas para as diferenças cognitivas entre homens e mulheres, tem no conceito de gênero parte do reconhecimento do caráter social $e$ historicamente construído das desigualdades fundamentadas sobre as diferenças físicas e biológicas.

As preferências não são meras características oriundas do corpo biológico, são construções sociais e históricas. Portanto, não é mais possível compreender as diferenças entre meninas e meninos com explicações fundadas na teoria do determinismo biológico e seu uso consequente da anatomia e da fisiologia como justificativas para as relações $e$ as identidades de gênero na sociedade moderna.

A desigualdade de gênero, ainda presente em nossa sociedade, afeta até mesmo as pesquisas sobre o desempenho e o desenvolvimento cognitivo de meninas e meninos. As afirmações biológicas sobre diferenças sociais nem sempre são cientificamente válidas, pois o conhecimento científico também é socialmente construído (Fausto-Sterlling, 2000; Citeli, 2001; Rohden, 2003). Gênero remete, então, à dinâmica de transformação social, aos significados que vão além dos corpos e do sexo biológico e que subsidiam noções, ideias e valores nas distintas áreas da organização social: podemos encontrá-los nos símbolos culturalmente disponíveis sobre masculinidade e feminilidade, heterossexualidade e homossexualidade; na elaboração de conceitos normativos referentes ao campo científico, político e jurídico; na formulação de políticas públicas implantadas em instituições sociais; nas identidades subjetivas e coletivas (Scott, 1995). Ele permite reconhecer a tendência à naturalização das 
relações sociais baseadas na fisiologia dos corpos e enxergá-los como signos impressos por uma sociedade e por uma cultura.

Ultrapassar a desigualdade de gênero pressupõe, assim, compreender o caráter social de sua produção, a maneira como nossa sociedade opõe, hierarquiza e naturaliza as diferenças entre os sexos, reduzindo-as às características físicas tidas como naturais e, consequentemente, imutáveis. Implica perceber que esse modo único e difundido de compreensão é reforçado pelas explicações oriundas das ciências biológicas e também pelas instituições sociais, como a família e a escola, que omitem o processo de construção dessas preferências, sempre passíveis de transformações.

\section{Gênero e educação infantil}

A Constituição de 1988 e a Lei de Diretrizes e Bases da Educação Nacional de 1996 garantem às crianças de 0 a 6 anos o direito de serem educadas fora de casa em creches e pré-escolas (Vianna; Unbehaum, 2006). A educação infantil (creche e préescola), como primeira etapa da Educação Básica, marca o início da experiência discente, quando as crianças terão oportunidade de conviver em um grupo social mais amplo, em uma instituição com características diferentes das do meio familiar. Essa etapa é palco de inscrições intelectuais, sociais e psicológicas. No convívio com os outros - educadores e colegas -, o corpo ganha destaque: os gestos, os movimentos $e$ as posturas são alinhavados socialmente; ganham determinado lugar e uma imagem, segundo padrões de conduta e valores culturais em que cada criança se insere.

$\mathrm{Na}$ educação infantil as crianças podem passar a maior parte do tempo em contato com outras crianças. É nessa relação singular que o protagonismo da criança ganha destaque e que a potencialidade do convívio, em suas diversas formas de relações, pode propiciar uma nova interação. Trata-se de um universo com características próprias, voltadas para crianças pequenas. Uma 
formatação com espaços, tempos, organizações e práticas construídos no seio das intensas relações entre crianças e entre crianças e adultos. Segundo Ana Lúcia Goulart de Faria (2006:87)

(...) neste espaço da sociedade vivemos as mais distintas relações de poder: gênero, classe, idade, étnicas. Desse modo é necessário estudar as relações no contexto educativo da creche e pré-escolas onde confrontam-se adultos - entre eles, professor/a, diretora, cozinheira, guarda, pai, mãe, secretário/a de educação, prefeito/a, vereador/a, etc.-; confrontam-se crianças, entre elas: menino, menina, mais velha, mais nova, negra, branca, judia, com necessidades especiais, pobre, rica, de classe média, católica, umbandista, atéia, "café com leite", "quatro olhos", etc.; e confrontam-se adultos e crianças - a professora $e$ as meninas, a professora e os meninos, o professor (percentual bastante baixo, mas existente e com tendência a lento crescimento) e os meninos, o professor $e$ as meninas, o professor e a mãe da menina.

$\mathrm{O}$ direito a uma educação infantil de qualidade inclui a discussão das questões de gênero. As relações das crianças na educação infantil apresentam-se como uma das formas de introdução de meninos e meninas na vida social, principalmente porque oferecem a oportunidade de estar em contato com crianças oriundas de diversas classes sociais, religióes e etnias com valores e comportamentos também diferenciados.

A educação infantil não só cuida do corpo da criança, como o educa: ele é o primeiro lugar marcado pelo adulto, em que se impõem à conduta dos pequenos os limites sociais $e$ psicológicos. É o emblema no qual a cultura inscreve seus signos.

Nosso corpo, nossos gestos e as imagens corporais que sustentamos são frutos de nossa cultura, das marcas e dos valores sociais por ela apreciados. O corpo - seus movimentos, posturas, ritmos, expressões e linguagens - é, portanto, uma construção social que se dá nas relações entre as crianças e entre estas e os 
adultos, de acordo com cada sociedade e cada cultura. Ele é produzido, moldado, modificado, adestrado e adornado segundo parâmetros culturais.

Torna-se, assim, indispensável pensar sobre práticas, habilidades e configurações corporais infantis e também sobre os modelos cognitivos nelas referenciados, como relações sociais de gênero, processadas, reconhecidas e valorizadas na e pela cultura na qual se inserem. É importante perguntar como esses mecanismos se fazem presentes na educação de meninas $e$ meninos; de que maneiras são inscritos em seus corpos, como normatizam, disciplinam, regulam e controlam seus comportamentos, posturas, verdades e saberes.

Homens e mulheres adultos educam crianças definindo em seus corpos diferenças de gênero. As características físicas e os comportamentos esperados para meninos e meninas são reforçados, às vezes inconscientemente, nos pequenos gestos $e$ práticas do dia-a-dia na educação infantil (Finco, 2003). Por exemplo, a forma como a família ou a professora conversa com a menina, elogiando sua meiguice ou como justifica a atividade sem capricho do menino. $O$ fato de pedir para uma menina a tarefa de ajudar na limpeza e ao menino para carregar algo já demonstra como as expectativas são diferenciadas. O que é valorizado para a menina não é, muitas vezes, apreciado para o menino, e vice-versa.

A experiência de meninas e meninos na educação infantil pode ser considerada como um rito de passagem contemporâneo que antecipa a escolarização, por meio da qual se produzem habilidades. $\mathrm{O}$ minucioso processo de feminilização $e$ masculinização dos corpos, presente no controle dos sentimentos, no movimento corporal, no desenvolvimento das habilidades $e$ dos modelos cognitivos de meninos e meninas está relacionado à força das expectativas que nossa sociedade e nossa cultura carregam. Esse processo reflete-se nos tipos de brinquedos que lhes são permitidos e disponibilizados: para que as crianças 
"aprendam", de maneira muito prazerosa e mascarada, a comportar-se como "verdadeiros" meninos e meninas.

Meninos e meninas desenvolvem seus comportamentos $e$ potencialidades a fim de corresponder às expectativas de um modo singular e unívoco de masculinidade e de feminilidade em nossa sociedade. Muitas vezes, instituições como familia, creches e pré-escolas orientam e reforçam habilidades específicas para cada sexo, transmitindo expectativas quanto ao tipo de desempenho intelectual considerado "mais adequado", manipulando recompensas e sanções sempre que tais expectativas são ou não satisfeitas. Meninas e meninos são educados de modos muito diferentes, sejam irmãos de uma mesma família, sejam alunos sentados na mesma sala, lendo os mesmos livros ou ouvindo a mesma professora. A diferença está nas formas aparentemente invisíveis com que familiares, professoras e professores interagem com as crianças.

As distinções podem ser percebidas, mas não são fixadas na característica biológica apresentada ao nascer. Os significados de gênero - habilidades, identidades e modos de ser - são socialmente configurados, impressos no corpo de meninos $e$ meninas de acordo com as expectativas de uma determinada sociedade. Se, por um lado, é possível observar o controle da agressividade na menina, o menino sofre processo semelhante, mas em outra direção: nele são bloqueadas expressões de sentimentos como ternura, sensibilidade e carinho. Os brinquedos oferecidos às crianças também estão carregados de expectativas, simbologias e intenções. As expectativas em relação à diferença de comportamento que se deseja para o menino e para a menina, justificadas pelas diferenças biológicas, acabam proporcionando distintas vivências corporais e determinando os corpos infantis: meninos e meninas têm no corpo a manifestação de suas experiências. Egle Becchi (2003) nos fala de uma "linguagem dos gestos": gestos ligados ao dia-a-dia, gestos do ato de brincar, gestos do corpo pelos movimentos corpóreos de aproximação, contato e exploração. Para a autora italiana, muito ainda deve ser 
estudado sobre linguagem gestual, uma "didática dos gestos", que penetra e caracteriza a pedagogia: o uso do corpo acariciado ou punido, as estratégias de vOz - o tom, o canto, o grito.

Contudo, pouco se questiona do caráter desse processo $e$ afirma-se que se trata de fato natural ligado ao sexo biológico. As transgressões que se apresentam, por mais numerosas que sejam, são consideradas exceções, e assim o preconceito não chega sequer a ser arranhado.

Desse modo, trazemos para reflexão as primeiras observações de pesquisa em andamento, realizada em uma préescola municipal de educação infantil (Emei) de São Paulo. Elas nos mostram as complexas interações entre professoras da educação infantil e crianças que transgridem as fronteiras de gênero.

\section{Comportamento e habilidades entre meninos e meninas: uma questão de gênero e poder}

Ao discutir os relatos de professoras e observar suas ações frente às meninas e aos meninos, este artigo trata das relações de gênero $e$ poder presentes nos processos de socialização de crianças pequenas $e$ analisa as estratégias voltadas para a normalização e o controle das expressões corporais de meninas e meninos. Ao buscar compreender como ocorria a educação de meninos e meninas que transgrediam as fronteiras do que lhes era imposto, verificamos como as características aparentemente naturalizadas e direcionadas à masculinidade e à feminilidade são resultantes de muitos esforços para deixar marcas distintas no corpo, no comportamento $e$ nas habilidades dessas crianças.

Desse modo, esta reflexão aborda como as formas de controle disciplinar de meninas e meninos estão intrinsecamente relacionadas ao controle do corpo, à demarcação das fronteiras entre feminino e masculino e ao reforço de características físicas e comportamentos tradicionalmente esperados para cada sexo nos pequenos gestos e nas práticas rotineiras da educação infantil. 
As interações observadas trazem consigo complexas relações de poder e evidentes tentativas de controle. As professoras da classe de pré-escola em foco, muitas vezes, orientam e reforçam diferentes habilidades nos meninos e nas meninas, de forma sutil, transmitindo expectativas quanto ao tipo de desempenho intelectual mais adequado para cada sexo $e$ manipulando sanções e recompensas sempre que tais expectativas sejam ou não satisfeitas. É também considerado comum que meninas e meninos desenvolvam seus comportamentos e potencialidades no sentido de corresponder às expectativas quanto às características mais desejáveis para o masculino e para o feminino. Esse aspecto aparece nos relatos de várias professoras entrevistadas:

Normalmente as meninas são mais tranquilas que os meninos. As meninas falam muito e os meninos são mais agitados assim com o corpo. As classes com mais meninos são mais agitadas. As meninas, eu costumo chamá-las de princesas, então é uma relação mais meiga, mais doce mesmo. E os meninos são os meus rapazes,... os meus rapazes são mais ativos, gostam de correr, de pular, não param quietos no lugar.

As meninas são mais meiguinhas, são mais dóceis, mais caprichosas, mais atenciosas. Os meninos gostam mais de brincar, são mais descuidados, mais agitados, tem uma diferença muito grande.

$\mathrm{Eu}$ não tenho um aluno que tem o capricho de muitas meninas, a maioria dos meus meninos faz as coisas de qualquer jeito, não tem cuidado, não é caprichoso, deixa as coisas jogadas, não tenho menina que deixa o estojo jogado no chão.

Os meninos não têm muita paciência para se apegar nos detalhes das atividades, eles querem acabar logo para poder brincar, para ficar livre. As meninas já são mais cuidadosas, se preocupam com detalhes. Elas se preocupam com o que eu vou achar do trabalho delas, os meninos não estão nem aí. 
Nas cores eles se prendem, o azul e o cor de rosa, a gente mesmo adulto acaba impondo isso, se você vir as portas dos banheiros é azul dos meninos e rosa das meninas.

Esse conjunto de expectativas e práticas faz com que a criança pequena que transgrida as fronteiras de gênero seja acompanhada e investigada profundamente de forma individual, tornando-se um "caso". Cria-se um sistema comparativo que estabelece informações que comporão as bases para o estabelecimento das normas. Esse sistema, além de classificar os indivíduos, estabelece sua relação com o coletivo. Com isso, cada criança que transgride é abordada na forma de um caso, um problema que é construído tanto do ponto de vista da produtividade, do poder, quanto do saber:

O caso é o indivíduo tal como pode ser descrito, mensurado, medido, comparado a outros $e$ isso em sua própria individualidade; e é também o indivíduo que tem que ser treinado ou retreinado, tem que ser classificado, normalizado, excluído, etc. (Foucault, 1977:70).

Assim, escolhemos dois relatos sobre dois casos de transgressões das fronteiras de gênero e as percepções sobre cada um deles. $\mathrm{O}$ "caso do menino que se veste de noiva" e o "caso da menina que usa tênis de dinossauro" são exemplos de vozes que ainda não se emudeceram, mesmo no interior de um sistema que procura normatizar as identidades de gênero das crianças.

\section{O menino que se vestia de noiva}

Tenho um caso de um menino que quer vestir vestido de noiva. A primeira vez ele chegou para mim e disse: "Coloca em mim este vestido de noiva?" Eu falei: "Nossa, esse vestido de noiva?" Ele me disse: É, é!" Então eu coloquei, não falei nada. Ele ficou rodando para lá e para cá com aquele vestido todo rendado, ficou um tempão com o vestido gostando muito. Já numa segunda vez eu falei: 
"Pega uma outra fantasia, você pega sempre a mesma, tem outras tão bonitas!" Ele insistiu, ele queria pôr e eu coloquei o vestido nele na segunda vez. Mas na terceira vez eu juro que não pus..., falei "Ah, vai lá, pega outra fantasia, essa não!", e ele foi lá e voltou com uma fantasia de rumbeira, aquelas coisas cheias de babados, ah meu deus! Eu ainda tentei dizer "Mas isso não te serve", tentei fazer com que ele esquecesse da fantasia, mas não adiantou. É muito difícil ele ir lá e pegar uma coisa que seja de menino, ele se atrai pelas fantasias de menina. Quando chega à brinquedoteca ele vai logo para as fantasias. Chegou um dia que ele vestiu o vestido e me disse que ia se casar com o Pedro, para mim foi o basta. Quer dizer que ele tinha a ideia que ali de noiva ele ia se casar com o Pedro, ele poderia falar que iria se casar com a Julia, ainda tudo bem, né? Mas não, ele dizia que ia se casar com o Pedro, ele era a noiva mesmo no caso. As outras crianças não deram muita atenção para ele com o vestido, não ligaram... Uma menina um dia passou $e$ disse "Ih, tia, olha!" Ela riu e já foi andando brincar com outra coisa. E para ele também não tem problema nenhum, ele riu também, para ela está tudo bem. Agora é difícil ele pegar o vestido, às vezes dá uma luz nele e ele pega o vestido, mas não é uma coisa que acontece constantemente, todo dia.

\section{A menina que usava tênis do dinossauro}

A mesma menina que gosta de jogar futebol, usa tênis com cores diferenciadas. Se é uma menina nos moldes normais não vai comprar um tênis bem masculino, vai comprar um tênis da Barbie, da Hello Kit. Não vai querer um tênis verde musgo com uma boca cheia de dentes na frente. Por isso nesse momento ela fugiria dos padrões normais. E para ela isso é muito tranquilo, e para as outras crianças da classe também, nunca ninguém fez um comentário, nem percebem. Ela é filha única, não tem irmão, não tem irmã. Ela fez o parâmetro dela, então ela fez a escolha dela. Não 
existe um modelo preestabelecido, se ela quiser chutar a bola em casa, pode.

Assim como no caso dos gestos, as vestes, as operações que o corpo deve efetuar no manuseio dos objetos requeridos pelo desenvolvimento da atividade são submetidas ao que Foucault (1977) descreve como outra forma de poder, a "articulação corpoobjeto": o vestido de noiva, o tênis de dinossauro. Existe uma prática de controle apresentada por meio de uma relação entre o corpo e o brinquedo.

As diferenças entre meninas e meninos, descritas pela professora entrevistada são justificadas como fruto da natureza, e não existe uma intencionalidade de propiciar a todos as mesmas oportunidades de acesso às várias dimensões da cultura infantil. Meninas não são incentivadas a jogar nos campeonatos de futebol da Emei; algumas vezes elas solicitam o auxílio da professora para mediar a relação com os meninos, mas esta não interfere, acreditando que esse não seja o seu papel. As professoras justificam que os meninos são "fominhas" de bolas; que as meninas preferem ficar assistindo ao jogo; que elas não sabem as regras do futebol, machucam-se, desanimam e acabam desistindo de jogar.

Se, por um lado, meninas podem ter sua identidade de gênero questionada se praticam futebol, com meninos o mesmo ocorre, se eles não o fazem, se não são fanáticos pelo seu time, se não têm um time. Meninos são como que obrigados a gostar de jogar futebol. Pais, mães, amigos, amigas e até educadores/as exercem uma "pressão social" para que pratiquem essa modalidade. Aqueles que não o fizerem podem ser vistos como femininos.

A análise dessas interações remete-nos à "vigilância hierárquica" definida por Foucault; ao controle sobre o corpo alheio, integrado por redes verticais de relações exercidas por dispositivos que obrigam pelo olhar, pela visibilidade dos submetidos e produzem efeitos de poder: "Acho que é o olhar do 
adulto que aponta o erro para as crianças, elas são inocentes, as crianças não percebem e não estão preocupadas com aquilo" (Entrevista 3).

Também se ressalta a "sanção normalizadora", caracterizada pela existência de um sistema duplo de recompensa $e$ de punição, instituído para corrigir e reduzir os desvios, especialmente mediante micropenalidades baseadas no tempo (atrasos, ausências), na atividade (desatenção, negligência) e em maneiras de ser (grosseria, desobediência). Esses métodos estão fundados em leis, programas e regulamentos, nos quais a reiteração de modelos determina a identificação dos sujeitos. $\mathrm{O}$ poder disciplinar permite o controle minucioso das operações do corpo e a sujeição constante de suas forças. A disciplina, arte de dispor em fila, individualiza os corpos por uma localização que não os implanta, mas os distribui e só faz circular numa rede de relações. A organização de lugares e fileiras cria espaços complexos: ao mesmo tempo arquitetônicos funcionais $e$ hierárquicos. São espaços que realizam a fixação e não permitem a circulação, marcam lugares e indicam valores, garantem a obediência dos indivíduos e uma melhor economia do tempo e dos gestos.

Não são somente os meninos que sofrem com essa forma de opressão. As meninas são igualmente punidas, pois elas carregam a obrigação de ser delicadas, organizadas e obedientes. Meninos e meninas desenvolvem seus comportamentos $e$ potencialidades no sentido de corresponder às expectativas quanto às características mais desejáveis para o que é definido como pertinente a um modelo singular e unívoco de masculinidade e de feminilidade em nossa sociedade.

Os significados de gênero são impressos nos corpos de meninos e meninas de acordo com as expectativas colocadas diariamente para as crianças, na forma como as professoras interagem com elas. Os corpos de meninas e meninos passam, desde muito pequenos, por um processo de feminilização $e$ 
masculinização, responsável por torná-los "mocinhas" ou "moleques" (Finco, 2007).

Contudo, mesmo quando a disciplina insiste em fabricar corpos submissos e afeitos aos padrões tradicionais de gênero, esses corpos, mesmo ainda pequenos, insistem em resistir $e$ rebelar-se. Meninos que se vestem de noiva, meninas consideradas abrutalhadas destoam das habilidades de gênero que muitas vezes as professoras insistem em reforçar, transmitindo expectativas quanto ao tipo de comportamento considerado "mais adequado" para cada sexo, manipulando recompensas e sanções sempre que tais expectativas são ou não satisfeitas.

Essas crianças nos mostram que é possível fazer educação produzindo diferenças, mesmo que isso se constitua em um grande desafio, pois a estranheza é o primeiro sentimento que as crianças transgressoras provocam nas professoras. Tal estranheza deriva da exposição do que todos esperavam que se mantivesse oculto e restrito. A criança transgressora desafia as normas pressupostas e coloca-as em discussão. Mostra, por suas ações, que masculinidades e feminilidades são construções sociais que também acontecem na Emei, que já chegou a separar meninos e meninas, com atividades distintas, contribuindo para fabricar sujeitos desiguais.

As preferências são construídas e a classe de pré-escola observada tende a contribuir para que as crianças pequenas sigam um padrão socialmente imposto do que seria certo ou errado, aceitável ou passível de rejeição. O modelo binário masculino-feminino é apresentado diariamente para elas. A manutenção desse modelo binário depende do ocultamento das masculinidades e feminilidades alternativas, do silêncio sobre elas e de sua marginalização. É por meio desses "maus exemplos" que a sociedade reforça a associação unívoca e supostamente natural entre sexo e padrões de gênero. Mas é também por meio deles que se convive com a diferença. Jeffrey Weeks (2003) afirma que, ao cruzar a fronteira dos padrões de comportamento 
considerados mais apropriados para homens e mulheres, pode-se adquirir o caráter de suprema transgressão.

A transgressão dos padrões socialmente aceitos costuma ser socialmente mal vista e ridicularizada, uma das maneiras mais eficientes de reafirmar que cada um teria que se conformar aos padrões tradicionais de gênero $e$, principalmente, ao lugar que lhe cabe na sociedade. São preconceitos que não resistem à razão, nem aos novos tempos e que continuamos a considerar verdades intocáveis, nos costumes e nas regras inflexíveis.

Entretanto, frente às opressões que as crianças vêm sofrendo, meninos e meninas ainda exercitam habilidades mais amplas, experimentam, inventam e criam, nos lembrando que o modo como estão sendo educados pode contribuir para limitar suas iniciativas e suas aspirações, mas também para se tornarem mais completos.

\section{Referências bibliográficas}

BECCHI, Egle. Ser menina ontem e hoje: notas para uma pré-história do feminino. Pro-Posições: Dossiê: Educação Infantil e gênero, vol.14, $\mathrm{n}^{\circ}$ 42, 2003, pp.41-52.

CITELI, Maria Teresa. Fazendo diferenças: teorias sobre gênero, corpo $e$ comportamento. Revista Estudos Feministas, vol. 9, Florianópolis, Centro de Filosofia e Ciências Humanas, UFSC, 2001, pp.131-145.

FARIA, Ana Lúcia Goulart de. Pequena infância, educação e gênero: subsídios para um estado da arte. Cadernos Pagu (26), Núcleo de Estudos de Gênero - Pagu/Unicamp, 2006, pp.279-288.

FAUSTO-STERLING, Anne. Sexing the body: gender politics and the construction of sexuality. New York, Basic Books, 2000.

Finco, Daniela. A educação dos corpos femininos e masculinos na Educação Infantil. In: Faria, Ana Lúcia G. de. O coletivo infantil em creches e pré-escolas: falares e saberes. São Paulo, Cortez, 2007.

. Faca sem ponta, galinha sem pé, homem com homem, mulher com mulher: relações de gênero nas relações de meninos $e$ 
Meninas e meninos na educação infantil

meninas na pré-escola. Dissertação de Mestrado, Faculdade de Educação, Universidade Estadual de Campinas, 2004.

. Relações de gênero nas brincadeiras de meninos e meninas na Educação Infantil. Pro-Posições: Dossiê: Educação Infantil e Gênero, vol. 14, n 42, 2003, pp.89-102.

FouCAULT, Michel. Vigiar e punir. Petrópolis, Vozes, 1977.

FRANGELlA, Simone Miziara. Fragmentos de corpo e gênero entre meninos e meninas de rua. Cadernos Pagu (14), Núcleo de Estudos de Gênero - Pagu/Unicamp, 2000, pp.201-234.

ROHDEN, Fabíola. A construção da diferença sexual na medicina. Cadernos de Saúde Pública, vol. 19 (Sup. 2), Rio de Janeiro, 2003, pp.201-212.

SCOTT, Joan Wallach. Gênero: uma categoria útil de análise histórica. Educação \& Realidade. vol. 20, n 2, Porto Alegre, 1995, pp.71-99.

SOARES, Carmen Lúcia. Imagens da educação no corpo; estudo a partir da Ginástica francesa no século XIX. Campinas-SP, Autores Associados, 1998.

e ZARANKIN, Andrés. Arquitetura e educação do corpo: notas indiciais. Revista Rua, n ${ }^{\circ}$ 10, 2004.

SOARES, Natália Fernandes. Investigação participativa no grupo social da infância. Currículos sem Fronteiras, vol. 6, $\mathrm{n}^{\circ}$ 1, jan.-jun. 2006, pp.25-40.

VAGo, Tarcísio Mauro. Cultura escolar, cultivo de corpos: Educação Physica e Gymnastica como práticas constitutivas dos corpos de crianças no ensino público primário de Belo Horizonte (1906-1920). Bragança Paulista-SP, EDUSF, 2002.

Veiga Neto, Alfredo. Currículo, disciplina e interdisciplinaridade. Revista Brasileira de Ciências do Esporte, vol. 17, n² 2, 1996, pp.128-137.

VIANNA, Cláudia; UnBeHAUM, Sandra. Gênero na educação básica: quem se importa? Uma análise de documentos de políticas públicas no Brasil. Educação \& Sociedade, vol. 27, n 95, maio-ago. 2006, pp.407-428. 
WEEKS, Jeffrey. O corpo e a sexualidade. In: LOURO, Guacira. (org.) O corpo educado: pedagogias da sexualidade. Belo Horizonte, Autêntica, 2003.

ZARANKIN, Andrés. Paredes que domesticam: arqueologia da arquitetura escolar capitalista. São Paulo, Fapesp, 2002. 